Özçakmak, H. ve Köroğlu, M. (2015) Türkçe öğretmeni adaylarının öğretmenlik mesleğine yönelik beklentileri. Ana Dili Eğitimi Dergisi, 3(4), 49-58.

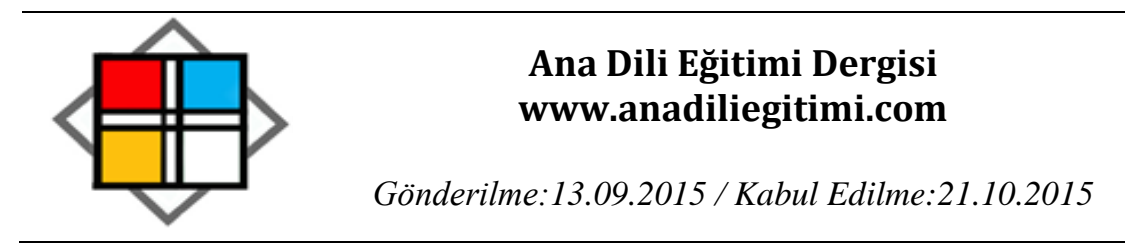

\title{
Türkçe Öğretmeni Adaylarının Öğretmenlik Mesleğine Yönelik Beklentileri
}

\author{
Hüseyin ÖZÇAKMAK* \\ Mustafa KÖROĞLU**
}

Öz

Türkçe öğretmeni adaylarının öğretmenlik mesleğinden beklentilerini belirlemeyi amaçlayan bu çalışma, 2014-2015 eğitim öğretim yılında Mustafa Kemal Üniversitesi Eğitim Fakültesi Türkçe Eğitimi Bölümü’nde öğrenim gören dördüncü sınıf öğretmen adayı 80 kişi ile gerçekleştirilmiştir. Çalışmada betimsel tarama modeli kullanılmıştır. Veriler, "Öğretmenlik mesleğinden beklentileriniz nelerdir?" şeklinde sorulan açık uçlu bir soru ile toplanmış, çalışmanın güvenirliğini sağlamak amacıyla, hem birinci hem de ikinci araştırmacı tarafından kodlanmıştır. Çalışmada toplanan veriler, nitel veri toplama ve çözümleme tekniklerinden içerik analizi ile çözümlenmiştir. Çalışmada başlıca şu sonuçlara ulaşılmıştır: 1) Öğretmen adaylarının çoğu, öğretmenlik mesleğine yönelik olumlu beklentiye sahiptir. 2) Bayan öğretmen adayları, öğretmen olarak atanacaklarına erkek öğretmen adaylarından daha fazla inanmaktadır. 3) Yüksek başarı düzeyine sahip öğretmen adayları, düşük ve orta seviye akademik başarı düzeyine sahip öğretmen adaylarına göre öğretmenlik mesleğ hakkında daha olumlu düşünmektedir.

Anahtar Kelimeler: Türkçe Öğretmeni Adayları, Öğretmenlik Mesleği, Beklenti.

\section{Expectations of Prospective Turkish Language Teachers from Teaching Profession}

\begin{abstract}
This study aimed to determine the expectations of prospective Turkish language teacher from the teaching profession, was carried out with 80 fourth-grade prospective Turkish language teachers at the Faculty of Education, Mustafa Kemal University in the academic year 2014-2015. Descriptive survey model was used in the study. The data were collected through an open-ended question asked such as "What are your expectations from the teaching profession?" and the data were encoded by both the first and second researcher for providing the reliability of the study. The data collected in this study were analyzed by using content analysis, one of the qualitative data collection and analysis techniques. The mainly conclusions reached in the study were summarized below: 1) Most of prospective teachers had positive expectations for the teaching profession. 2) Female prospective teachers believed their appointment as a teacher more than male prospective teachers. 3) Prospective teachers with high level of achievement had more positive thoughts about the teaching profession according to prospective teachers with low and moderate level of success. Keywords: Prospective Turkish Language Teachers, Teaching Profession, Expectation.
\end{abstract}

\footnotetext{
*Dr., Mustafa Kemal Üniversitesi Eğitim Fakültesi Türkçe Eğitimi Bölümü, Hatay.

E-posta: h.ozcakmak@hotmail.com

${ }^{* *}$ Arş. Gör., Mustafa Kemal Üniversitesi Eğitim Fakültesi Türkçe Eğitimi Bölümü, Hatay.

E-posta: koroglumustafa z@hotmail.com
} 


\section{Giriş}

Beklenti, Türkçe Sözlük'te “Gerçekleşmesi beklenen şey. Bireyin belli şartlar ve durumların alacağı biçimler veya kendisinden beklenenler konusundaki öngörüsü." (TDK, 2011: 296) şeklinde tanımlanmıştır. Oxford Sözlük'te ise "Bir şeyin olacağına veya öyle olduğuna yönelik güçlü inanç" olarak ifade edilmiştir (Oxford, 2010: 615). Tanımlar gözden geçirildiğinde, beklenti tanımında hem öngörü hem de inanç kavramlarının öne çıktığı görülmektedir. Bu yönleriyle değerlendirildiğinde, beklenti kavramının gelecekte olacakların alelade bir tahmini olmanın ötesinde, olacaklar hakkındaki güçlü bir inancı da ortaya koyduğu anlaşımaktadır.

Edward Chace Tolman tarafından geliştirilen Beklenti Kuramı'na göre, birey amacına ulaşmak için davranışlarını değiştirebilir, farkılışan koşulları gözden geçirerek farklı şekilde davranabilir. Tolman'a göre, bireyi amacına ulaştıran denenceler, bireyin beklentisinin doğrulanmasını sağlar. Beklentilerin güçlenmesi ise davranışı güçlendirir (Senemoğlu, 2013: 216). Öğretmen adaylarının en büyük beklentisi, öğretmen olarak atanmaktır. Bu amaca ulaşmak için yıllarca çalışmak, lise ve üniversitede birçok dersten başarılı olmak zorundadırlar.

Öğretmenlik beklentisi ile eğitim fakültelerini seçen ve öğretmenlik bölümüne yerleşen öğretmen adaylarının önünde başarıyla tamamlamaları gereken üniversite süreci bulunmaktadır. Ancak bölümü bitirmekle öğretmen adaylarının yıllardır beklediği öğretmenlik hayali hemen gerçekleşmez. Bunun için Kamu Personeli Seçme Sınavı'na (KPSS) girmeli ve bu sınavdan kendi branşı için gerekli olan minimum atanma puanını almalıdırlar. Bu süreçte, başta aileleri olmak üzere, çevresinde bulunan birçok kimsenin çeşitli beklentilerle sordukları sorular onları psikolojik açıdan yıpratmaya başlar. Bilhassa ilk senesinde atanamayan bazı öğretmen adayları için bu sorular giderek sorun hâline dönüştüğü için cesaretleri kırılır ve öğretmen olmaya olan inançları gittikçe azalır.

Yapılan bir çalışmada, Türkçe öğretmen adaylarının en fazla şikâyet ettikleri konuların başında $\% 40,2$ oranı ile atanamama sorununun geldiği tespit edilmiştir (Aslan, 2010). Ayrıca çeşitli üniversitelerin eğitim fakülteleri temel alınarak yapılan araştırmalarda; öğretmen adaylarının başlıca stres kaynaklarının atanma kaygısı olduğunun belirlenmesi (Akpınar, 2013), öğretmen adaylarının çoğunun KPSS'yi kendileri için ruhen yıpratıcı bir süreç (Gündoğdu, Çimen ve Turan, 2008) ve gelecekleri için kaygılanma aracı olarak görmesi (Sezgin ve Duran, 2011), öğretmen adaylarının atanamama kaygısı yaşadıklarını açıkça ortaya koymaktadır.

Öğretmen adaylarının öğretmenlik mesleğini seçmelerinde etkili olan faktörler konusunda yapılan araştırmalara bakıldığında, öğretmenlik mesleğinin kutsal ve saygın bir meslek olarak görüldüğ̈̈; öğretme arzusunu tatmin etmesi, yeni bir nesil yetiştirmeye fırsat vermesi ve toplumun kalkınmasında etkili bir meslek olması nedeniyle tercih edildiği görülmektedir (Erdem ve Şimşek, 2000; 
Özbek, 2007; Semerci, 1999; Tarman, 2012). Ayrıca adı geçen çalışmalarda, öğretmen adaylarının öğretmenliği sorumluluk ve fedakârlık gerektiren bir meslek olarak gördükleri de ulaşılan bulgular arasında yer almaktadır. Zorlu bir süreci tamamlayarak öğretmenliğe başlayan öğretmen adaylarının, öğretmen olma isteklerini daima diri tutmaları, süreç boyunca yaşayacakları olumsuzlukların üstesinden gelmeleri gerekmektedir. Böylelikle, mesleklerinden soğumayacaklar, öğretmenlikle ilgili beklentilerine kavuşabileceklerdir.

Öğretmenlik mesleği, bilgi ve beceri kazanmanın yanı sıra tutum ve alışkanlıkları da gerektirmektedir. Bu sebeple, eğitim fakültelerinde öğrenim gören öğretmen adaylarının meslekle ilgili değer ve tutum kazanmaları, en az bilgi edinmek kadar önem arz eden bir husus olmaktadır (Çeliköz ve Çetin, 2004). Öğretmen adaylarının mesleklerine yönelik tutumları, onların mesleklerini sevmelerini; mesleklerinin gerekli ve önemli olduğu bilinciyle kendilerini sürekli geliştirmelerini sağlamaktadır. Bu konuda sahip oldukları olumlu ya da olumsuz tutumlar, öğretmen adaylarının meslekî davranışlarını yönlendirmede etkili olmaktadır (Temizkan, 2008). Bu nedenle, öğretmen adaylarının öğrenme yaşantıları öğretmenlik mesleğine yönelik olumlu tutumlar oluşturacak biçimde düzenlenmelidir.

Beklentiler, bir tutumun davranışa yansıyıp yansımayacağını belirleyen önemli faktörlerdir. Bir tutumun kuvvetinin az olması, davranışa dönüşme olasılığını da azaltacaktır. Kuvvetli olmayan bir tutum, ortamsal engeller ve olumsuz beklentiler karşısında zayıflayacağı için davranışa dönüşemez (Aydın, 2003: 285). Beklentilerin yeni denencelerle desteklenmesi, öğretmen adaylarının mesleklerine yönelik olumlu tutumlar geliştirmelerini de hızlandıracaktır. Yaşar Ekici (2014) tarafından yapılan bir araştırma da bu düşünceyi desteklemektedir. Bu araştırmada, öğretmen olma beklentisi ile eğitim fakültesine gelen öğretmen adaylarının; iş garantisi, çalışma koşulları veya ailesinin isteği nedeniyle öğretmenliği tercih eden öğretmen adaylarına göre öğretmenlik mesleği konusunda daha olumlu bir tutuma sahip oldukları ortaya konmuştur.

Öğretmen adayları için öğretmenlik mesleğinden beklentiler atanmayla sınırlı değildir. Atanma konusu, öğretmen adayları için geçilecek ilk kapı olma mahiyetindedir ve esas beklentiler atandıktan sonra başlamaktadır. Öğretmenlik mesleğinin; öğrenci, meslektaş, okul, sınıf gibi birçok bileşkeden oluştuğu göz önüne alındığında, öğretmen adaylarının öğretmenlikten beklentileri de çeşitlenecektir. Bu çalışmanın amacı, Türkçe öğretmen adaylarının öğretmenlik mesleğine yönelik olumlu veya olumsuz beklentilerini bu boyutları göz önüne alarak belirlemektir. Böylelikle Türkçe öğretmen adaylarının; mesleği, atanma inancı, atandığı yer, atandığı okul, öğrencileri ve meslektaşları ile ilgili düşüncelerinin tespit edilmesi amaçlanmıştır. Ayrıca, çalışmanın amaçları arasında, Türkçe öğretmen adaylarııın öğretmenlik mesleğine yönelik beklentilerin cinsiyet ve başarı düzeyine göre dağılımlarının belirlenmesi de yer almaktadır. 


\section{Yöntem}

Yöntem bölümü, çalışma modeli, çalışma grubu ile veri toplama ve çözümleme tekniklerinden oluşmaktadır.

\section{Çalışma Modeli}

Türkçe öğretmeni adaylarının öğretmenlik mesleğinden beklentilerinin belirlenmesini amaçlayan bu çalışmada betimsel tarama modeli kullanılmıştır. Tarama modelleri, geçmişte ya da halen var olan bir durumu var olduğu şekliyle betimlemeyi amaçlar (Karasar, 2009: 77-79). Çalışmada toplanan veriler, nitel veri toplama ve çözümleme tekniklerinden içerik analizi kullanılarak çözümlenmiştir. İçerik analizinde temelde amaç, birbirine benzeyen verileri belli kavram ve temalar etrafında bir araya getirerek düzenlemektir (Yıldırım ve Şimşek, 2011: 227).

\section{Çalışma Grubu}

2014-2015 eğitim öğretim yılında Mustafa Kemal Üniversitesi Eğitim Fakültesi Türkçe Eğitimi Bölümü’nün dördüncü sınıfında öğrenim gören 80 öğretmen adayı, araştırmanın çalışma grubunu oluşturmaktadır. Çalışmada 2,70'in altında ortalamaya sahip öğrenciler düşük; 2,70'ten 3,00'a kadar ortalaması olan öğrenciler orta; 3,00 ve üzerinde ortalaması olan öğrenciler ise yüksek akademik başarılı olarak kabul edilmiştir. Çalışmaya katılan öğretmen adaylarının cinsiyet ve başarı düzeyine göre dağılımı aşağıdaki gibidir.

Tablo 1: Çalışma Grubunun Cinsiyet ve Akademik Başarıya Göre Dağılımı

\begin{tabular}{lcccccc}
\hline & \multicolumn{2}{c}{ Bayan } & \multicolumn{2}{c}{ Erkek } & \multicolumn{2}{c}{ Toplam } \\
\cline { 2 - 7 } Başarı Düzeyi & $\mathrm{f}$ & $\%$ & $\mathrm{f}$ & $\%$ & $\mathrm{f}$ & $\%$ \\
\hline Düşük & 11 & 13 & 20 & 25 & 31 & 39 \\
Orta & 14 & 18 & 14 & 18 & 28 & 35 \\
Yüksek & 12 & 15 & 9 & 11 & 21 & 26 \\
Toplam & 37 & 46 & 43 & 54 & 80 & 100 \\
\hline
\end{tabular}

Tablo 1'e göre çalışmaya katılan öğrencilerin $\% 46$ 'sı bayan, $\% 54$ 'ü erkek öğretmen adaylarından oluşmaktadır. Ayrıca çalışma grubunun \%39'unun düşük, \%35'inin orta, \%26'sının ise yüksek akademik başarıya sahip olduğu tabloda görülmektedir.

\section{Veri Toplama ve Çözümleme Teknikleri}

Çalışmada veriler, "Öğretmenlik mesleğinden beklentileriniz nelerdir?" şeklinde sorulan açık uçlu bir soru ile toplanmıştır. Bunun yanı sıra öğretmen adaylarının cinsiyet ve akademik başarı ortalamalarına yönelik bilgileri de temin edilmiştir. Çalışmanın güvenirliğini sağlamak amacıyla, veriler hem birinci hem de ikinci araştırmacı tarafından kodlanmış, farklılıklar üzerinde tartışılarak kodlamalar konusunda tamamen fikir birliğine varılmıştır. Öğretmen adaylarının yazdıkları metinler; öğretmenlik mesleği, atanma inancı, atanılan yer, atanılan okul, öğrenciler ve meslektaşlar olmak üzere 6 ana 
kategoriye ayrılmış, her bir kategori altında tespit edilen farklı düşünceler ayrı ayrı kodlanmıştır. Ayrıca öğretmen adaylarının beklentilerinin cinsiyet ve başarı düzeyine göre farklılık gösterip göstermediğini belirlemek amacıyla analizler yapılmıştır. Tespit edilen bulgular, frekans ve yüzde kullanılarak aşağıda ifade edilmiştir.

\section{Bulgular}

Bulgular bölümünde, Türkçe öğretmeni adaylarının öğretmenlik mesleğine, atanma inancına, atanılan yere, atanılan okula, öğrencilerine ve meslektaşlarına yönelik beklentileri ele alınmıştır. Ayrıca bu bölümde Türkçe öğretmeni adaylarının beklentileri cinsiyet ve akademik başarı açısından değerlendirilmiştir.

Tablo 2: Öğretmenlik Mesleğine Yönelik Düşünceler

\begin{tabular}{llrr}
\hline & & $f$ & $\%$ \\
\hline \multirow{2}{*}{ Olumlu Düşünceler } & Mesleğimi severek yaparım. & 42 & 71 \\
& Öğretmenlik benim çocukluk hayalimdir. & 13 & 22 \\
\hline Olumsuz Düşünceler & Öğretmen olmak istemiyorum. & 4 & 7 \\
\hline Toplam & & 59 & 100 \\
\hline
\end{tabular}

Tablo 2 gözden geçirildiğinde, bu konuda görüş bildiren öğretmen adaylarının ( $f=59$ ) büyük çoğunluğunun ( $f=55)$ öğretmenlik mesleği konusunda olumlu düşündüğü; az sayıda $(f=4)$ öğretmen adayının ise bu konuda olumsuz görüşe sahip olduğu görülmektedir.

Tablo 3: Öğretmen Adaylarının Atanmaya Yönelik Düşünceleri

\begin{tabular}{lrrrr}
\hline & & Atanamam & & Atanırım \\
\cline { 2 - 5 } Cinsiyet & $\mathrm{f}$ & $\%$ & $\mathrm{f}$ & $\%$ \\
\hline Bayan & 2 & 5,4 & 35 & 94,5 \\
Erkek & 5 & 11,6 & 38 & 88,4 \\
Toplam & 7 & 8,8 & 73 & 92,3 \\
\hline
\end{tabular}

Yukarıdaki tablo incelendiğinde, öğretmen adaylarının büyük çoğunlukla ( $f=73)$ atanma inancına sahip olduğu, bayan öğretmen adaylarının erkek öğretmen adaylarına göre atanacaklarına nispeten daha fazla inandıkları göze çarpmaktadır.

Tablo 4: Öğretmen Adaylarının Atanılan Yerle Ilgili Düşünceleri

\begin{tabular}{lrrr}
\hline Atandığı Yer & $\mathbf{f}$ & \% \\
\hline Köy & & 8 & 38 \\
Kasaba & 6 & 29 \\
Şehir & & 7 & 33 \\
Toplam & Güzel bir yere atanırım. & 21 & 100 \\
\hline Olumlu Düşünceler & Atandığım yere yabancılık çekerim. & 7 & 33 \\
\hline \multirow{2}{*}{ Olumsuz Düşünceler } & İstediğim yere atanamam. & 9 & 43 \\
Toplam & & 5 & 24 \\
\hline
\end{tabular}


Tablo 4'e göre 21 kişinin, atanacağı yerle ilgili görüş bildirdiği, bu kişilerin çoğunluğunu köye atanacağını düşünenlerin $(f=8)$ oluşturduğu görülmektedir. Atandığı yer hakkında olumlu düşünenlerin en fazla Güzel bir yere atanırım ( $\mathrm{f}=7$ ); olumsuz düşünenlerin ise en çok Atandığım yere yabancılık çekerim şeklinde görüş beyan ettikleri tablodan anlaşılmaktadır.

Tablo 5: Öğretmen Adaylarının Atanılan Okulla IIlgili Düşünceleri

\begin{tabular}{llrr}
\hline & & $\mathbf{f}$ & \multicolumn{1}{c}{$\%$} \\
\hline \multirow{2}{*}{ Olumlu Düşünceler } & Okulumu severim. & 6 & 33 \\
& Okulum kaldığım yere yakın olur. & 5 & 28 \\
\hline \multirow{2}{*}{ Olumsuz Düşünceler } & Okulun fiziki durumu çok kötü olur. & 5 & 28 \\
& Okulu bulmakta zorlanırım. & 2 & 11 \\
\hline Toplam & & 18 & 100 \\
\hline
\end{tabular}

Tablo 5 gözden geçirildiği zaman, öğretmen adaylarının atandığı okulla ilgili 18 görüş bildirdiği görülmektedir. Bu görüşler arasında olumlu olanların en çok Okulumu severim ( $f=6)$; olumsuz görüşlerin ise en fazla Okulun fizikî durumu çok kötü olur $(\mathrm{f}=5)$ düşüncesi etrafında toplandığı anlaşılmaktadır.

Tablo 6 : Öğretmen Adaylarının Öğrencileriyle IIlgili Düşünceleri

\begin{tabular}{llrr}
\hline & & $\mathbf{f}$ & \% \\
\hline \multirow{3}{*}{ Olumlu Düşünceler } & Öğrencilerle iyi anlaşırım. & 49 & 41 \\
& Sınıfı iyi yönetirim. & 13 & 11 \\
& Çalışkan öğrencilerim olacak. & 6 & 5 \\
\hline & Ders anlatırken stresli olurum. & 29 & 24 \\
& Öğrenciler konusunda hayal kırıklığı yaşarım. & 7 & 6 \\
Olumsuz Düşünceler & Sınıflar kalabalık ve gürültülü olur. & 6 & 5 \\
& Illk gün çok yorulurum. & 6 & 5 \\
& Sınıfı kontrol etmekte zorlanırım. & 4 & 3 \\
\hline Toplam & & 120 & 100 \\
\hline
\end{tabular}

Tablo 6'ya göre, öğretmen adayları, öğrencileri ile ilgili 120 görüş bildirmiştir. Bu görüşler arasında en fazla frekansa sahip olumlu görüş Öğrencilerle iyi anlaşırım ( $f=49$ ); en fazla frekansa sahip olumsuz görüş ise Ders anlatırken stresli olurum ( $\mathrm{f}=29$ ) şeklinde ortaya çıkmıştır.

Tablo 7: Öğretmen Adaylarının Meslektaşlarıyla ilgili Düşünceleri

\begin{tabular}{llrr}
\hline & & $\mathbf{f}$ & $\mathbf{\%}$ \\
\hline \multirow{3}{*}{ Olumlu Düşünceler } & Meslektaşlarımla iyi geçinirim. & 10 & 42 \\
& Meslektaşlarım ilk gün beni samimi karşılar. & 8 & 33 \\
& Meslektaşlarım yardımsever olur. & 6 & 25 \\
\hline Toplam & & 24 & 100 \\
\hline
\end{tabular}

Yukarıdaki tablo değerlendirildiğinde, öğretmen adaylarının meslektaşlarıyla ilgili değerlendirmelerinde olumsuz herhangi bir görüşe rastlanmadığı, olumlu görüşler arasında ise en fazla Meslektaşlarımla iyi geçinirim ( $f=10$ ) düşüncesinin öne çıktığı görülmektedir. 
Türkçe Öğretmeni Adaylarının Öğretmenlik Mesleğine Yönelik Beklentileri

Tablo 8: Öğretmenlik Mesleğine Yönelik Beklentilerin Cinsiyete Göre Dağılımı

\begin{tabular}{lrrrrrr} 
& \multicolumn{2}{c}{ Olumlu } & \multicolumn{3}{c}{ Olumsuz } & \multicolumn{3}{c}{ Toplam } \\
\cline { 2 - 7 } Cinsiyet & $\mathrm{f}$ & $\%$ & $\mathrm{f}$ & $\%$ & $\mathrm{f}$ & $\%$ \\
\hline Bayan & 85 & 69,1 & 38 & 30,9 & 123 & 100 \\
Erkek & 80 & 63,5 & 46 & 36,5 & 126 & 100 \\
Toplam & 165 & 66,3 & 84 & 33,7 & 249 & 100 \\
\hline
\end{tabular}

Tablo 8 gözden geçirildiğinde, öğretmenlik mesleğine yönelik olumlu beklentilerin olumsuz beklentilere göre daha fazla olduğu ( $f=165 / f=84)$ görülmektedir. Ayrıca öğretmenlik mesleğine yönelik beklentiler açısından, bayan öğretmen adaylarının erkek öğretmen adaylarından daha fazla olumlu beklenti sergiledikleri ( $\mathrm{f}=85 / \mathrm{f}=80$ ) tablodan anlaşılmaktadır.

Tablo 9: Öğretmenlik Mesleğine Yönelik Beklentilerin Başarı Düzeyine Göre Dağılımı

\begin{tabular}{lrrrrrr} 
& \multicolumn{2}{c}{ Olumlu } & \multicolumn{3}{c}{ Olumsuz } & \multicolumn{3}{c}{ Toplam } \\
Başarı Düzeyi & $f$ & $\%$ & $f$ & $\%$ & $f$ & $\%$ \\
\hline Düşük & 55 & 66,3 & 28 & 33,7 & 83 & 100 \\
Orta & 59 & 64,1 & 33 & 35,9 & 92 & 100 \\
Yüksek & 51 & 68,9 & 23 & 31,1 & 74 & 100 \\
Toplam & 165 & 66,3 & 84 & 33,7 & 249 & 100 \\
\hline
\end{tabular}

Tablo 9'a göre, yüksek başarı düzeyine sahip öğretmen adayları, düşük ve orta seviye akademik başarıya sahip öğretmen adaylarına göre, öğretmenlik mesleği hakkında daha olumlu $(\% 68,9)$ düşünmektedirler.

\section{Sonuçlar}

Çalışmadan elde edilen sonuçlar şu şekilde özetlenebilir:

Öğretmenlik mesleğine yönelik düşüncesini ifade eden öğretmen adaylarının çoğu (\%71) mesleğini severek yapacağını belirtmiştir. Öğretmen adaylarının büyük çoğunluğu $(\% 92,3)$ öğretmen olarak atanacaklarına inanmaktadırlar. Çalışmamızın bulguları, Temizkan'ın (2008) Türkçe öğretmeni adayları üzerinde gerçekleştirdiği çalışmanın bulguları ile benzerlik göstermektedir. Bu çalışmada, Türkçe öğretmen adaylarının \%85'inin, zor şartlarda da olsa öğretmenlik yapmaktan mutlu olacakları tespit edilmiştir. Başkonuş, Akdal ve Taşdemir (2011) tarafından yapılan diğer bir çalışmada, öğretmen adaylarının atanma konusunda ifade ettikleri görüşler arasından en fazla frekansı "Atanacağım konusunda umutluyum." görüşünün alması çalışmamızın bulgularını destekler mahiyettedir. Diğer taraftan atanma konusunda Şahin (2011) tarafından yapılan bir çalışmada ise çalışmamızdan farklı bulgulara ulaşılmıştır. Çalışmada, öğretmen adaylarının \%81'inin meslekî gelecekleri konusunda olumsuz düşüncelere sahip oldukları; yalnızca \%19'unun meslekî gelecekleri, öğretmen atamaları ve KPSS konusunda olumlu düşünceler taşıdıkları tespit edilmiştir.

Atanacağı yerle ilgili görüş bildiren öğretmen adaylarının \%38'i köye, \%33'ü şehir merkezine, \%29'u ise kasabaya atanacağını düşünmektedir. Öğretmen adayları arasında köye atanacağını 
düşünenlerin daha fazla olmasında, atanan öğretmen sayısının yetersizliği etkili olmuş olabilir. Her yıl binlerce kişinin mezun olmasına karşılık çok azının öğretmen olarak atandığı göz önüne alındığında, öğretmen adaylarının köy ve kasaba demeksizin Türkiye'nin her yerine gitmeyi göze almaları doğal görünmektedir. Bu konuda Şahin (2011) tarafından gerçekleştirilen bir çalışma elde edilen bulgular bu görüşü destekleyici niteliktedir. Bu çalışmada, öğretmen adaylarının \%66'sının, ülkenin her yerinde görev yapabileceği ortaya konmuştur. İşsiz kalma, koşulların zorlaması, idealist düşünceler ve milliyetçi duygular ise ülkenin her yerinde görev yapma nedenleri olarak ileri sürülmüştür.

Çalışmamızda, öğretmen adaylarının atanacakları yer konusunda olumlu ve olumsuz beklentiler içinde oldukları tespit edilmiştir. Buna göre öğretmen adaylarının bazıları güzel bir yere atanacağını (\%33); bazıları atandığı yere yabancılık çekeceğini (\%43), bazıları ise istediği yere atanamayacağını (\%24) düşünmektedir. Bunların yanı sıra, atanacağı okulla ilgili görüş belirten öğretmen adaylarının \%33'ü atandığı okulu seveceği, \%28'i ise atandığı okulun fizikî açıdan çok kötü durumda olacağı inancındadır. Öğretmen adaylarının çoğunun köy veya kasabaya atanacağı beklentisi içinde oldukları göz önüne alındığında, en fazla dile getirilen olumsuz beklentilerin; istediği yere atanamama, atandığı yere yabancılık çekme ve atandığı okulun fizikî açıdan çok kötü olması şeklinde ortaya çıkması oldukça doğal karşılanmalıdır.

Öğrencileriyle ilgili düşüncesini ifade eden öğretmen adaylarının \%41'i öğrencilerle iyi anlaşacağına inanmaktadır. Weinstein (1988) tarafından yapılan araştırmanın bulguları, çalışmamızı bir yönüyle desteklemektedir. Bu çalışmada, öğretmen adaylarının gelecekteki öğrencileri hakkında olumlu düşüncelere sahip oldukları; farklı kültürde olan öğrencilerle öğretim yapma, sınıf disiplinini sağlama ve bireysel farklılıkları idare etme konularında yüksek beklenti içinde oldukları tespit edilmiştir.

Meslektaşları hakkında fikir belirten öğretmen adaylarının \%42'si meslektaşlarıyla iyi geçineceğini; \%33'ü ise meslektaşlarının ilk gün kendilerini samimi karşılayacağını düşünmektedir. Bu durumda, meslektaşları konusunda olumlu beklentiye sahip öğretmen adayının sayıca yeterli olmadığı söylenebilir. Uğurlu, Kıral ve Aksoy (2011) tarafından yapılan bir çalışmada, öğretmenlerin \%59'unun yeni başlayan öğretmenlerin okula ve görevine uyum sağlaması konusunda okul yönetimin gereken hassasiyeti yeterince göstermediğini belirtmiş olmaları, çalışmamızla örtüşen bir bulgudur. Yeni başlayan öğretmenlere, mesleklerinin ilk günlerinde hem okul yönetimi hem de öğretmen arkadaşları tarafından yardım edilmelidir. Böylelikle bu öğretmenlerin okullarını sevmeleri ve meslektaşlarıyla uyum içinde çalışmaları daha çabuk gerçekleşecektir.

Çalışmamızda cinsiyet açısından yapılan analizlerde, öğretmenlik mesleği hakkında, bayan öğretmen adaylarının $(\% 69,1)$ erkek öğretmen adaylarına $(\% 63,5)$ göre daha olumlu düşündükleri belirlenmiştir. Yapılan çalışmalarda (Akman, 1992; Erden, 1990; Gömleksiz, Kan ve Biçer, 2010; Özbek, 
Kahyaoğlu ve Özgen, 2007) öğretmenlik mesleğine yönelik beklentiler açısından bayan öğretmen adaylarının erkek öğretmen adaylarına göre daha olumlu olduklarının belirlenmesi çalışmamızı destekler niteliktedir. Kim ve Cho (2014) tarafından yapılan çalışmada, erkek öğretmen adaylarının öğretmenlik mesleğinin ilk yılında gerçeklik şoku yaşama beklentisinin bayan öğretmen adaylarına göre daha fazla olduğu sonucuna ulaşılması da çalışmamızı destekler niteliktedir.

Son olarak, çalışmamızda, aralarında çok az fark olmakla birlikte, yüksek akademik başarı düzeyine sahip öğretmen adaylarının $(\% 68,9)$ orta $(\% 64,1)$ ve düşük $(\% 66,3)$ başarı düzeyine sahip öğretmen adaylarına göre öğretmenlik mesleği hakkında daha olumlu düşündükleri belirlenmiştir. Bu durum akademik başarının, öğretmen adaylarının öğretmenlik mesleğine yönelik beklentilerini olumlu yönde etkilediğini ortaya koyması açısından önemlidir.

\section{Kaynakça}

Akman, Y. (1992). Hacettepe Üniversitesi eğitim fakültesi öğrencilerinin meslek, evlilik ve geleceğe yönelik beklentileri. Hacettepe Üniversitesi Eğitim Fakültesi Dergisi, 7(7), 125-149.

Akpınar, B. (2013). Öğretmen adaylarının stres düzeylerinin çeşitli değişkenler açısından incelenmesi. Dicle Üniversitesi Ziya Gökalp Eğitim Fakültesi Dergisi, 21, 229-241.

Aslan, C. (2010). Türkçe öğretmenleri ve öğretmen adaylarının sorunları üzerine çevrimiçi paylaşım alanlarındaki (forum) iletilere dayalı bir çözümleme. NWSA: Education Sciences, 5(4), 2254-2269.

Aydın, O. (2003). Tutumlar. E. Özkalp (Ed.), Davranış bilimlerine giriş̧ (279-296). Eskişehir: Anadolu Üniversitesi Yayınları.

Başkonuş, T., Akdal, D. ve Taşdemir, M. (2011). Ahi Evran Üniversitesi eğitim fakültesi son sınıf öğrencilerinin gelecek beklentileri. 2nd International Conference on New Trends in Education and Their Implications (ss. 1512-1522). Ankara: Siyasal Kitabevi.

Çeliköz, N. ve Çetin, F. (2004). Anadolu öğretmen lisesi öğrencilerinin öğretmenlik mesleğine yönelik tutumlarını etkileyen etmenler. Millî Eğitim Dergisi, 162

Erdem, A. R. ve Şimşek, S. (2000, Mayıs). PAÜ eğitim fakültesi öğrencilerinin öğretmenliği seçmelerinde etkili olan faktörler. II. Ulusal Öğretmen Yetiştirme Sempozyumu'nda sunulmuş sözlü bildiri. Onsekiz Mart Üniversitesi, Çanakkale.

Erden, M. (1990). Hacettepe Üniversitesi eğitim bilimleri bölümü öğrencilerinin meslekleri ile ilgili beklentileri. HÜ Eğitim Fakültesi Dergisi, 4-5, 245-257.

Gömleksiz, M. N., Kan, A. Ü. ve Biçer, S. (2010). Öğretmen adaylarının öğretmenlik mesleğinden beklentileri (Fırat Üniversitesi örneği). E-Journal of New World Sciences Academy Education Sciences, 5(2), 479-500.

Gündoğdu, K., Çimen, N. ve Turan, S. (2008). Öğretmen adaylarının kamu personeli seçme sınavına (KPSS) ilişkin görüşleri. Ahi Evran Üniversitesi Kırşehir Eğitim Fakültesi Dergisi, 9(2), 35-43.

Karasar, N. (2009). Bilimsel araştırma yöntemi. Ankara: Nobel Yayın Dağııım.

Kim, H. \& Cho, Y. (2014). Pre-service teachers' motivation, sense of teaching efficacy, and expectation of reality shock. Asia-Pacific Journal of Teacher Education, 42(1), 67-81.

Oxford. (2010). Oxford dictionary of English. Oxford University Press (Third Edition).

Özbek, R. (2007). Öğretmen adaylarının öğretmenlik mesleğini tercih etmelerinde kişisel, ekonomik ve sosyal faktörlerin etkililik derecesine ilişkin algıları. Fırat Üniversitesi Sosyal Bilimler Dergisi, 17(1), 145-159.

Özbek, R., Kahyaoğlu, M. ve Özgen, N. (2007). Öğretmen adaylarının öğretmenlik mesleğine yönelik görüşlerinin değerlendirilmesi. Sosyal Bilimler Dergisi, 9(2), 221-232. 
Semerci, Ç. (1999). Öğrencilerin öğretmenlik mesleğine ilişkin tutum ölçeği. Eğitim ve Bilim, 23(111), 51-55.

Senemoğlu, N. (2013). Gelişim, öğrenme ve öğretim: Kuramdan uygulamaya. Ankara: Yargı Yayınevi.

Sezgin, F. ve Duran, E. (2011). Kamu Personeli Seçme Sınavı'nın (KPSS) öğretmen adaylarının akademik ve sosyal yaşantılarına yansımaları. Türkiye Sosyal Araştırmalar Dergisi, 15(3), 9-22.

Şahin, i. (2011). Prospective teachers' ideas about teacher recruitment and their professional future. Educational Sciences: Theory \& Practice, 11(3), 1179-1184.

Tarman, B. (2012). Prospective teachers' beliefs and perceptions about teaching as a profession. Educational Sciences: Theory and Practice, 12(3), 1964-1973.

TDK. (2011). Türkçe sözlük. Ankara: Türk Dil Kurumu.

Temizkan, M. (2008). Türkçe öğretmeni adaylarının öğretmenlik mesleğine yönelik tutumları üzerine bir araştırma. Türk Eğitim Bilimleri Dergisi, 6(3), 461-486.

Uğurlu, Z., Kıral, E. ve Glsen Aksoy, İ. (2011). İlköğretim okul yöneticilerinin görüşlerine göre öğretmenlerin sosyalleşmesinde kullandıkları örgütsel sosyalleşme strateji ve taktikleri. 2nd International Conference on New Trends in Education and Their Implications (ss. 706-719). Ankara: Siyasal Kitabevi.

Weinstein, C. S. (1988). Preservice teachers' expectations about the first year of teaching. Teaching and Teacher Education, 4(1), 31-40.

Yaşar Ekici, F. (2014). Öğretmen adaylarının öğretmenlik mesleğine yönelik tutumlarının çeşitli değişkenler açısından incelenmesi (İstanbul Sabahattin Zaim Üniversitesi örneği). Uluslararası Sosyal Araştırmalar Dergisi, 7(35), 658-665.

Yıldırım, A. ve Şimşek, H. (2011). Sosyal bilimlerde nitel araştırma yöntemleri. Ankara: Seçkin Yayıncılık. 